\title{
Comprehensive understanding of vascular anatomy for endovascular treatment of intractable oronasal bleeding
}

\author{
Sungjun Moon \\ Department of Radiology, Kyungpook National University School of Medicine, Daegu, Korea
}

\begin{abstract}
Oronasal bleeding that continues despite oronasal packs or recurs after removal of the oronasal packs is referred to as intractable oronasal bleeding, which is refractory to conventional treatments. Severe craniofacial injury or tumor in the nasal or paranasal cavity may cause intractable oronasal bleeding. These intractable cases are subsequently treated with surgical ligation or endovascular embolization of the bleeding arteries. While endovascular embolization has several merits compared to surgical ligation, the procedure needs attention because severe complications such as visual disturbance or cerebral infarction can occur. Therefore, comprehensive understanding of the head and neck vascular anatomy is essential for a more effective and safer endovascular treatment of intractable oronasal bleeding.
\end{abstract}

Keywords: Intractable; Bleeding; Epistaxis; Embolization; External carotid artery

\section{INTRODUCTION}

Approximately $60 \%$ of the adult population has experienced at least one episode of epistaxis during their lifetimes. Fortunately, in most cases, the bleeding stops spontaneously, and only $6 \%$ of patients require medical care [1]. Prevalence of epistaxis is equal between males and females. Distribution of age shows a mild peak before 20 years and a prominent increase after 40 years of age [2,3]. Epistaxis is classified into anterior and posterior bleeding, depending on the location of the occurrence. Most cases of epistaxis occur at the watershed area of the anterior nasal septum, known as the Little area. As this area is easily accessible, anterior nasal bleeding can usually be controlled by anterior nasal packing or local

Received: April 9, 2018, Revised: April 26, 2018 Accepted: May 11, 2018

Corresponding Author: Sungjun Moon, Department of Radiology, Kyungpook National University School of Medicine, 130, Dongdeok-ro, Jung-gu, Daegu 41944, Korea

Tel: +82-53-200-5390, Fax: +82-53-422-2677

E-mail: msj31218@gmail.com treatment [4]. Posterior bleeding less commonly occurs at the posterior watershed area [5]. When posterior nasal bleeding occurs, the success rate of using nasal packs has been reported to be between $48 \%$ and $83 \%$ [6-9].

Oronasal bleeding that continues despite oronasal packs or recurs after removal of the oronasal packs is referred to as intractable oronasal bleeding. Packing failure is due to the posterior location that makes it more difficult to access, absence of a hard structure to support the packing in patients with comminuted fracture, and large connective pathway between the oral and nasal cavities, resulting from a wide range of facial bone fractures.

These intractable cases are subsequently treated by surgical ligation or endovascular embolization of the bleeding arteries. Although the external coronary artery can be surgically ligated, it is not always effective because of the rich collateral cir culation of external carotid artery [10-12]. By contrast, endovascular embolization has several advantages. One can approach from the distal portion of the bleeding site, identify the bleeding site, and control multiple bleeding sites. Furthermore, general anesthesia is not needed and the procedure

Copyright (C) 2018 Yeungnam University College of Medicine

This is an Open Access article distributed under the terms of the Creative Commons Attribution Non-Commercial License (http://creativecommons.org/licenses/by-nc/4.0/) which permits unrestricted non-commercial use, distribution, and reproduction in any medium, provided the original work is properly cited. 
takes a short time $[9,11,13-16]$. However, the procedure needs attention because complications such as involuntary migration of an embolic material, loss of vision, facial paralysis, and soft tissue necrosis may occur. As intractable oronasal bleeding is an urgent case, neuroradiologists should acquire full knowledge of the accurate anatomy for a safer and more effective treatment.

\section{External carotid artery}

The external carotid artery supplying the extracranial head and neck, and intracranial meninges gives off 8 branches as follows: superior thyroid, ascending pharyngeal, lingual, facial, occipital, posterior auricular, internal maxillary, and superficial temporal arteries. Among these branches, the internal maxillary, ascending pharyngeal, facial, lingual, and superior thyroidal arteries are related oronasal bleeding, which is also related to the ethmoidal artery, which branches off the ophthalmic artery of the internal carotid artery and supplies the nasal cavity roof. During embolization for oronasal bleeding, neuroradiologists should identify which vessels are bleeding and in which vessels severe complications occur, such as cerebral infarction or visual disturbance through dangerous anastomoses. These dangerous anastomoses are relevant to the internal maxillary, ascending pharyngeal, and facial arteries among the branches of the external carotid artery (Table 1).

\section{Nasal cavity supply}

The sphenopalatine artery is the terminal branch of the distal internal maxillary artery and the main branch supplying the nasal cavity (Fig. 1). Anterior and posterior ethmoidal arteries branching off the ophthalmic artery of the internal carotid artery supply the roof of the nasal cavity dominantly. Descending palatine artery branching off the distal internal

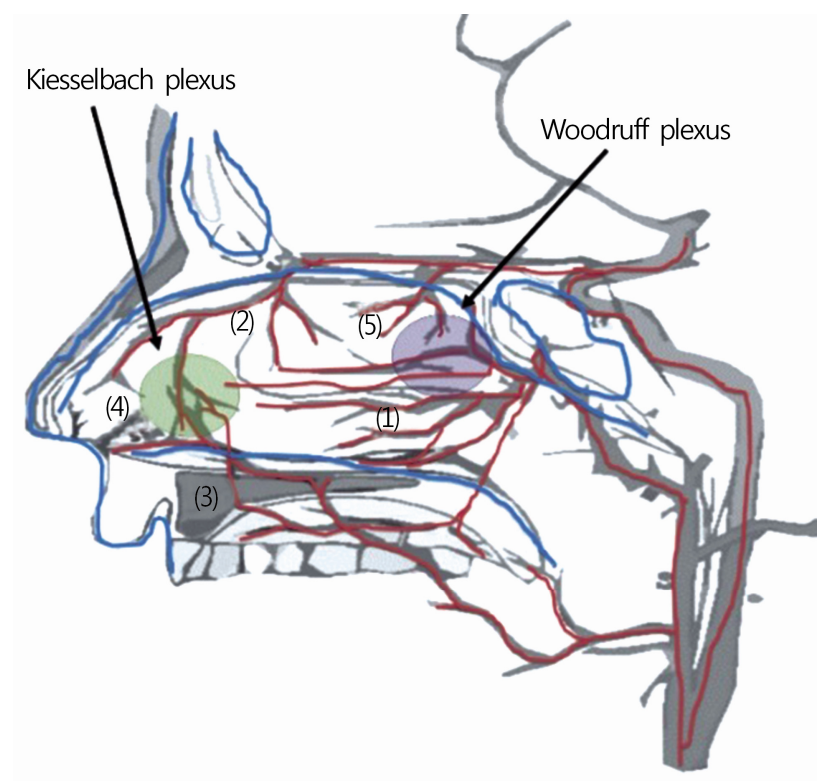

Fig. 1. Blood supply of nasal cavity. (1) Sphenopalatine, (2) anterior ethmoidal, (3) greater palatine, (4) superior labial, and (5) posterior ethmoidal arteries.

Table 1. Major extracranial and intracranial anastomoses

\begin{tabular}{|c|c|}
\hline Extracranial artery & Intracranial artery \\
\hline Sphenopalatine artery of IMA & Anterior/posterior ethmoidal artery of $\mathrm{OA}$ \\
\hline Infraorbital artery of IMA & Inferior branch of distal lacrimal artery of OA \\
\hline Anterior deep temporal artery of IMA & Inferior branch of distal lacrimal artery of OA \\
\hline Middle meningeal artery of IMA & Recurrent meningeal artery of proximal lacrimal artery of OA \\
\hline Middle meningeal artery of IMA & Posterolateral branch of ILT \\
\hline Accessory meningeal artery of IMA & Posteromedial branch of ILT \\
\hline Artery of foramen rotundum of IMA & Anterolateral branch of ILT \\
\hline Vidian artery of IMA & Mandibular artery of petrous ICA \\
\hline Superior pharyngeal artery of pharyngeal trunk of AphA & Recurrent artery of foramen lacerum of ILT or MHT \\
\hline Hypoglossal and jugular branch of neuromeningeal trunk of AphA & Lateral clival artery \\
\hline Odontoid arcade of neuromeningeal trunk of AphA & Vertebral artery \\
\hline Angular artery of facial artery & Dorsal nasal artery of $\mathrm{OA}$ \\
\hline
\end{tabular}

IMA, internal maxillary artery; AphA, ascending pharyngeal artery; OA, ophthalmic artery; ILT, inferolateral trunk; MHT, meningohypophyseal trunk; ICA, internal carotid artery. 
maxillary artery supplies the floor of the nasal cavity dominantly, anastomosing with the ascending palatine artery branching off the facial artery $[17,18]$.

Anterior epistaxis accounted for $95 \%$ of all cases of epistaxis; and posterior epistaxis, for 5\% [5]. Nasal bleeding more commonly occurs at the anterior watershed area, known as the Kiesselbach plexus, which consists of the sphenopalatine artery, anterior ethmoidal artery, greater palatine artery of the descending palatine artery, and superior labial artery of the facial artery. Posterior bleeding less commonly occurs at the posterior watershed area, known as the Woodruff plexus, which consists of the sphenopalatine and posterior ethmoidal arteries $[17,18]$.

\section{Internal maxillary artery}

The internal maxillary artery goes anteriorly through the space between the sphenomandibular ligament and ramus of the mandible, passing by the superficial or deep pterygoid muscle and then reaching the apex of the sphenopalatine fossa. It is divided into three segments by the lateral pterygoid muscle as follows: the mandibular, zygomatic (or pterygoid), and pterygopalatine segments $[19,20]$. Internal maxillary artery is an important vascular structure not only for intractable oronasal bleeding but also for dangerous anastomoses that result in severe complications (Fig. 2).

First segment (or mandibular segment) is located before the lateral pterygoid muscle, which runs vertically and turns horizontally, going below the auriculotemporal nerve and coming along with the internal maxillary vein [21]. It branches off the anterior tympanic, middle meningeal, accessory meningeal, and inferior alveolar arteries.

Attention should be paid to dangerous anastomoses of the first segment, that is, in the middle and accessory meningeal arteries. Middle meningeal artery runs through the foramen spinosum and branches off the anterior convexity branches, posterior convexity branches, petrosquamosal branch, and petrosal branch, which supply most dura mater and facial nerves [19]. Anterior branch of the middle meningeal artery communicates with the ophthalmic artery via the recurrent meningeal artery through the superior orbital fissure and meningolacrimal artery through the canal of Hyrtl, and the petrosal branch of the middle meningeal artery also has anastomosis with the posterolateral branch of the inferolateral trunk [19,22-24]. The accessory meningeal artery usually arises directly from either the middle meningeal artery or the mandibular or pterygoid segments of the internal maxillary. It runs anterosuperomedially, giving off its major terminal rami before the foramen ovale that supply the extracranial structures in this region. Then, it enters the cranium through the fora-

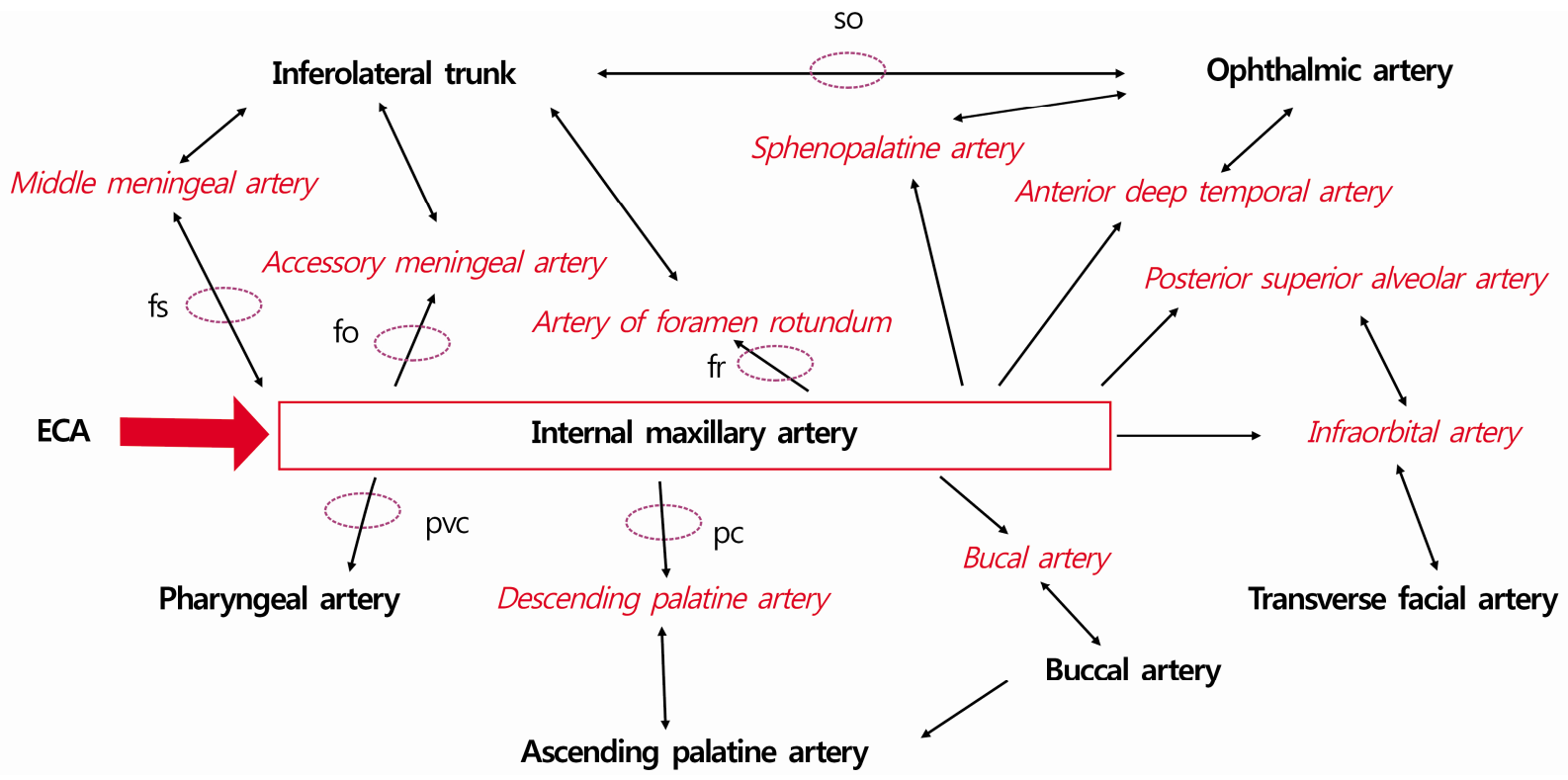

Fig. 2. Internal maxillary collateral via the foramen or canal. so, superior orbital fissure; fs, foramen spinosum; fo, foramen ovale; fr, foramen rotundum; ECA, external carotid artery; pvc, palatovaginal canal; pc, palatine canal. 
men ovale and supplies the trigeminal ganglion and adjacent dura mater $[25,26$. It passes through the foramen ovale and communicates with the posteromedial branch of the inferolateral trunk $[19,22,23]$.

The second (zygomatic or pterygoid) segment has two courses, namely the superficial and deep courses. The superficial course passes lateral to the lateral pterygoid muscle, and the deep course passes medial to the lateral pterygoid muscle [19]. The former is more common than the latter, accounting for approximately $60 \%$ of the total course [27]. The superficial course usually arise from the middle and accessory meningeal arteries together by forming a common trunk, but the deep course usually arise from the middle and accessory meningeal arteries separately [22]. It branches off the anterior deep temporal, middle deep temporal, pterygoid, masseteric, and buccal arteries.

Anterior deep temporal artery can form dangerous anastomoses with the ophthalmic artery via the inferior branch of the lacrimal artery, which runs anterosuperiorly and supplies the temporal muscle [22,28-30].

The third (pterygopalatine) segment turns transversely at the entrance to the pterygopalatine fossa and reaches the apex of the fossa [19]. This segment goes inferiorly to the maxillary nerve and comes along with the maxillary vein. The third segment branches as follows: the posterior superior alveolar artery, infraorbital artery, descending palatine artery, sphenopalatine artery, pharyngeal (or palatovaginal) artery, artery of the foramen rotundum, and artery of the pterygoid canal (or Vidian artery).

The 2 most important branches related to oronasal bleeding in this segment are the sphenopalatine and descending palatine arteries. The sphenopalatine artery goes through the sphenopalatine foramen and into the nasal cavity, and divides into both the medial and lateral branches supplying the wide region of the nasal cavity (Fig. 3). Lateral branches supply the nasal turbinates, and the medial branches supply the nasal septum [31,32]. Sphenopalatine artery communicates with the anterior and posterior ethmoidal arteries branching off the lacrimal artery of the ophthalmic artery, which is frequently observed in large juvenile angiofibromas [22,33].

The descending palatine artery runs inferiorly, enters the pterygopalatine canal, and comes out of the greater and lesser palatine foramen, divided into the greater and lesser palatine arteries, respectively. The greater palatine artery supplies the hard palate mainly. Its terminal branch through the incisive foramen supplies the anterior nasal septum being part of the Kiesselbach plexus, or the Little area [20]. The lesser palatine artery supplies the soft palate and palatine tonsils (Fig. 4).

The infraorbital artery runs below the orbit, gives off several orbital branches just before entering the infraorbital
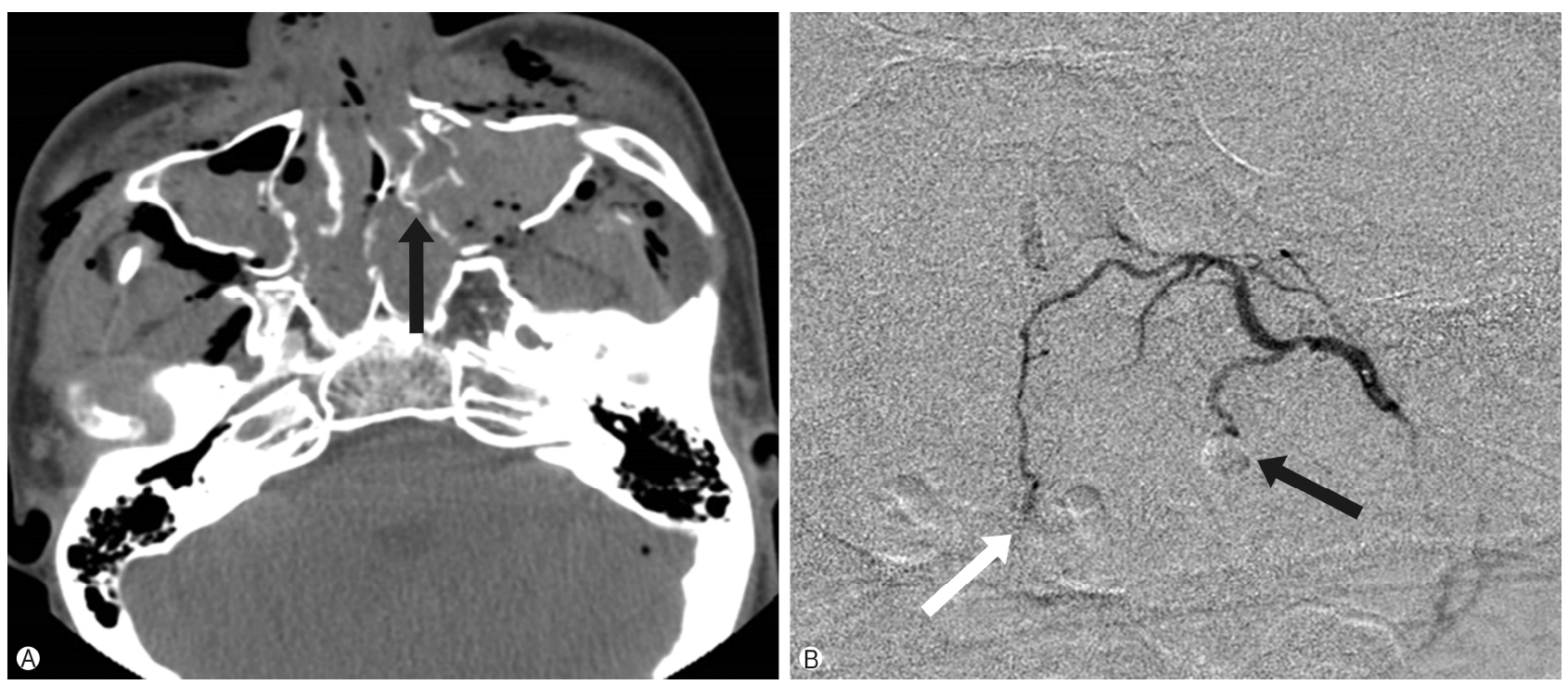

Fig. 3. A 20-year-old man with Le Fort II and mandibular fracture. (A) Computed tomography scan of the face shows multiple fractures of turbinates (black arrow). (B) Superselective angiogram (lateral view) of the left sphenopalatine artery shows extravasation of the contrast material from the lateral (black arrow) and medial (white arrow) branches. Medial or septal branches supply the septum, and the lateral branches supply the turbinates. 

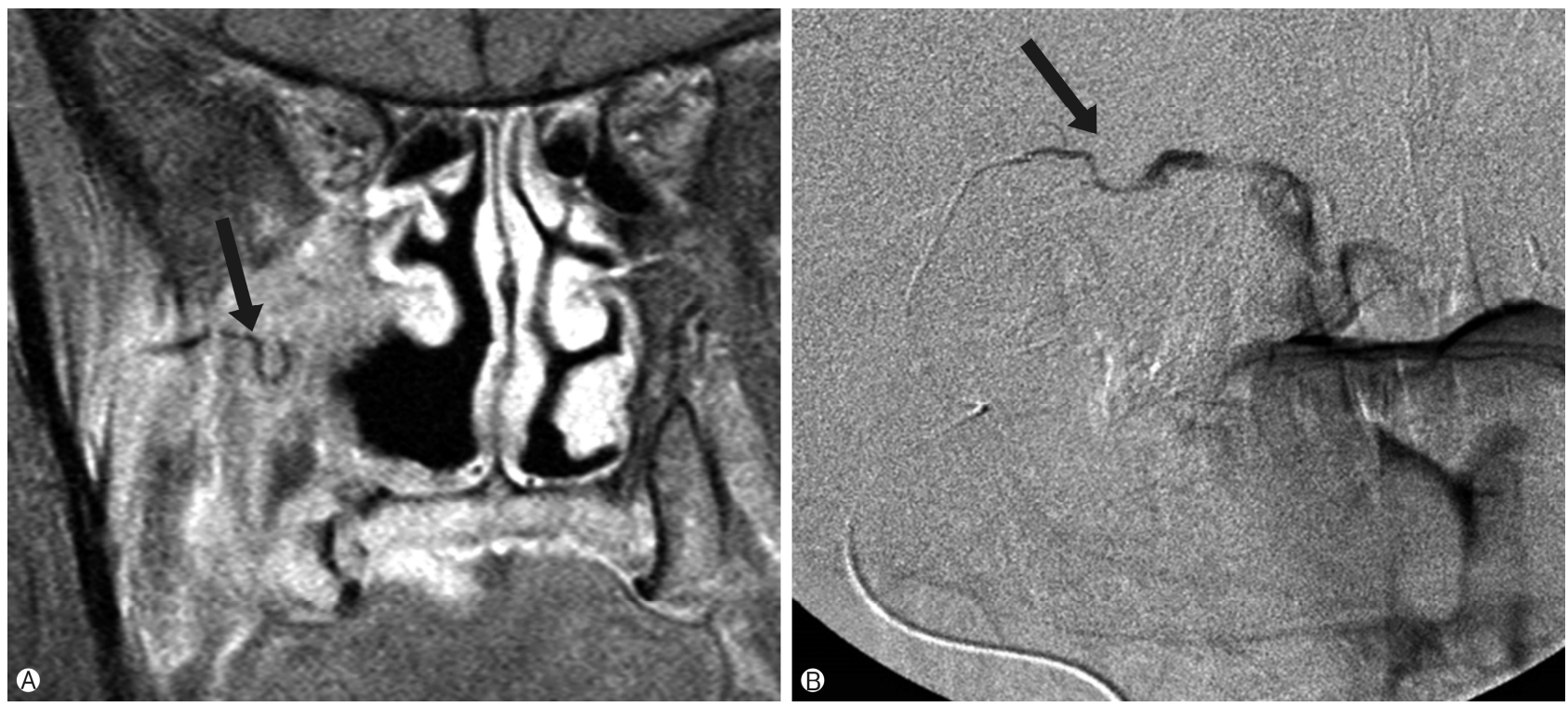

Fig. 4. A 56-year-old man with maxillary sinus carcinoma, post operation and radiotherapy. (A) Magnetic resonance imaging scans of the face show an enlarged and curved vascular structure (black arrow) in the destructed posterior portion of the right maxillary sinus. (B) Superselective angiogram of the lesser palatine artery (black arrow) shows the same shape as that on the magnetic resonance image and extravasation of the contrast material into the oral cavity.

canal, and passes through the infraorbital foramen (Fig. 5). Among these branches, the medial branch group supplies the inferior eyelids and nasolacrimal canal, and communicates with the inferior muscular and inferior medial palpebral arteries [34]. Among these branches, the anterior superior alveolar artery supplies the upper incisors and mucous membrane of the maxillary sinus anastomosing with the posterior superior alveolar artery of the internal maxillary artery [35]. After passing through the infraorbital foramen, the end of the infraorbital canal, its branches communicate with the branches of the facial artery or transverse facial artery [36].

In this third segment, dangerous anastomoses are related to the Vidian artery and artery of foramen rotundum. The former runs horizontally and forms the Vidian anastomotic system, which consists of the mandibular artery of the petrous internal carotid artery, accessory meningeal artery, and superior pharyngeal branches of the ascending pharyngeal artery [37-40]. The latter runs through foramen rotundum, which appears as a corkscrew and anastomoses with the anterolateral branch of the inferolateral trunk (Fig. 6) [41,42].

\section{Ascending pharyngeal artery}

The ascending pharyngeal artery is important in multiple clinical situations such as trauma, epistaxis, high-grade head

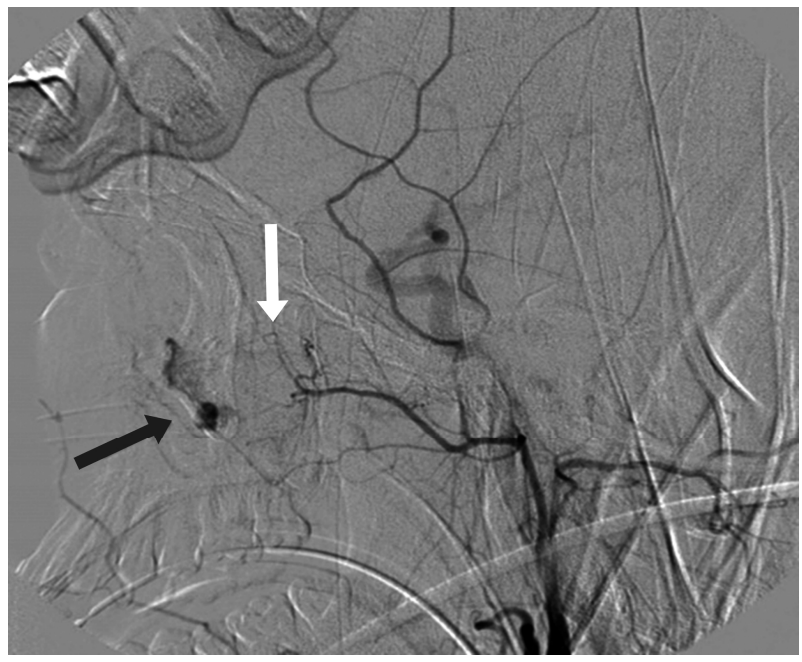

Fig. 5. A 19-year-old man with a zygomaticomaxillary fracture. External carotid angiogram shows contrast extravasation and pseudoaneurysm (black arrow) from the branches of the infraorbital artery (white arrow), which may anastomose with the posterior superior alveolar and transverse facial arteries.

and neck tumors, and vascular malformation. It divides into the pharyngeal trunk, located anteriorly and extracranially, and the neuromeningeal trunk, located posteriorly and intracranially (Fig. 7). The latter enters the posterior fossa through the foramen magnum. Pharyngeal trunk branches into the superior, middle, and inferior pharyngeal arteries supplying the pharyngeal mucosal spaces, which include the Eustachian 
tube and fossa of the Rosenmuller fossa $[43,44]$. Neuromeningeal trunk subdivides into the hypoglossal and jugular branches supplying the meninges of the posterior fossa and the vasa nervorum of cranial nerves XII, IX, X, and XI, respectively $[45,46]$.

Several dangerous anastomoses also occur between the ascending pharyngeal artery and branches of the internal carotid artery (Fig. 8). The superior pharyngeal branches of the pharyngeal trunk are part of the previously mentioned Vidian anastomotic system and communicate with the recurrent ar- tery of the foramen lacerum, which usually branches off the inferolateral trunk but may also branch off the meningohypophyseal trunk $[19,22,44]$. Among the branches of the neuromeningeal trunk, hypoglossal and jugular branches communicate with the meningohypophyseal trunk supplying the hypoglossal and jugular nerves, respectively. The odontoid arcade, which usually arises from the proximal cervical portion of the neuromeningeal trunk and may arise from the main ascending pharyngeal artery, communicates with the vertebral artery $[44,47,48]$.
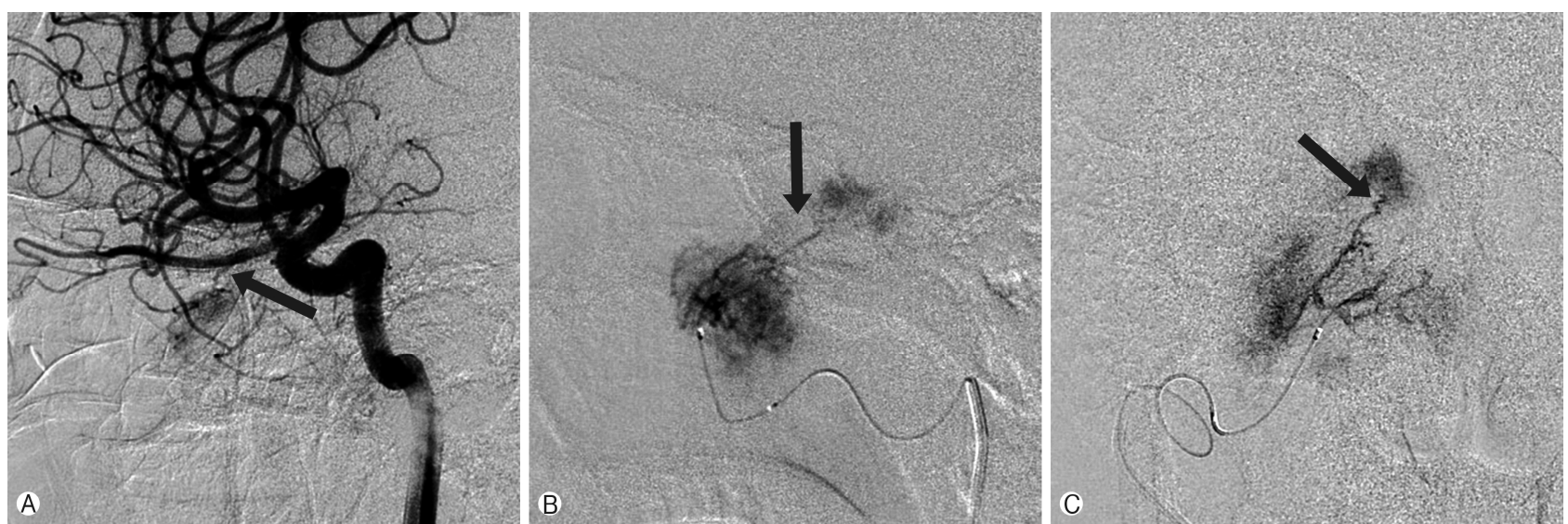

Fig. 6. A 20-year-old man with angiofibroma. (A) Right internal carotid angiogram (lateral view) shows partial tumor staining by the hypertrophic posterior ethmoidal artery (black arrow) of the ophthalmic artery. (B, C) Superselective angiogram (lateral and anteroposterior views) shows the artery of the foramen rotundum (black arrow) appearing as a corkscrew and supplying the tumor.
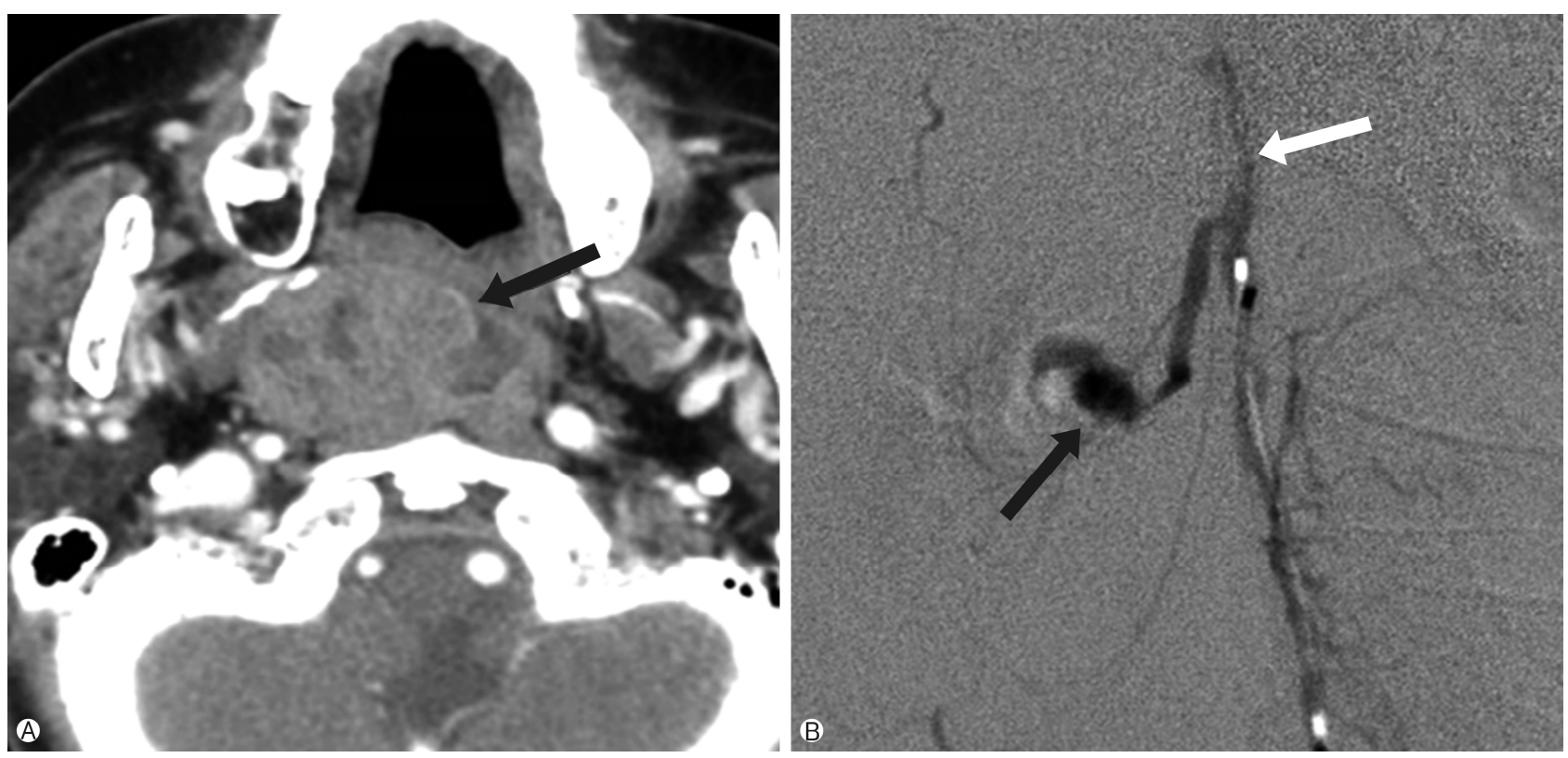

Fig. 7. A 67-year-old man with a pleomorphic adenoma, post operation. (A) Preoperative neck computed tomography scan shows a retropharyngeal mass (black arrow). (B) Superselective angiogram of the ascending pharyngeal artery shows a pseudoaneurysm (black arrow) from the superior pharyngeal artery from the pharyngeal and neuromeningeal trunk (white arrow). 


\section{Facial, lingual, and superior thyroid arteries}

The incidence of cases where the facial, lingual, and superior thyroid arteries branch separately is reported to be $56.3 \%$, and that of cases of a common trunk of the facial and lingual arteries is reported to be $31.3 \%$. Cases with a common trunk of the superior thyroid and lingual arteries account for $12.5 \%$ of cases [49].

Facial artery can divide into cervical and facial segments. Cervical segment includes the ascending palatine artery, ton-
Meningohypophyseal trunk

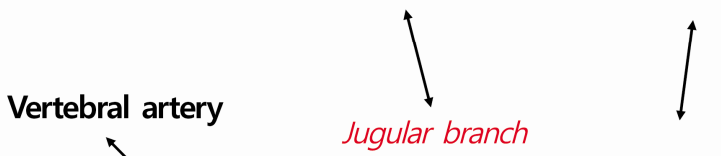

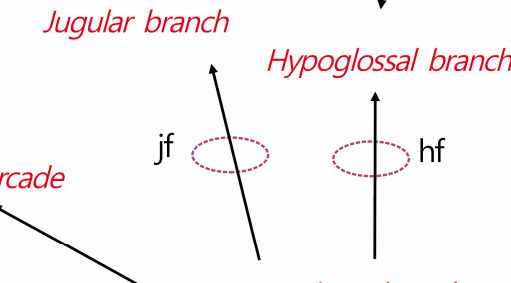

Neuromeningeal trunk
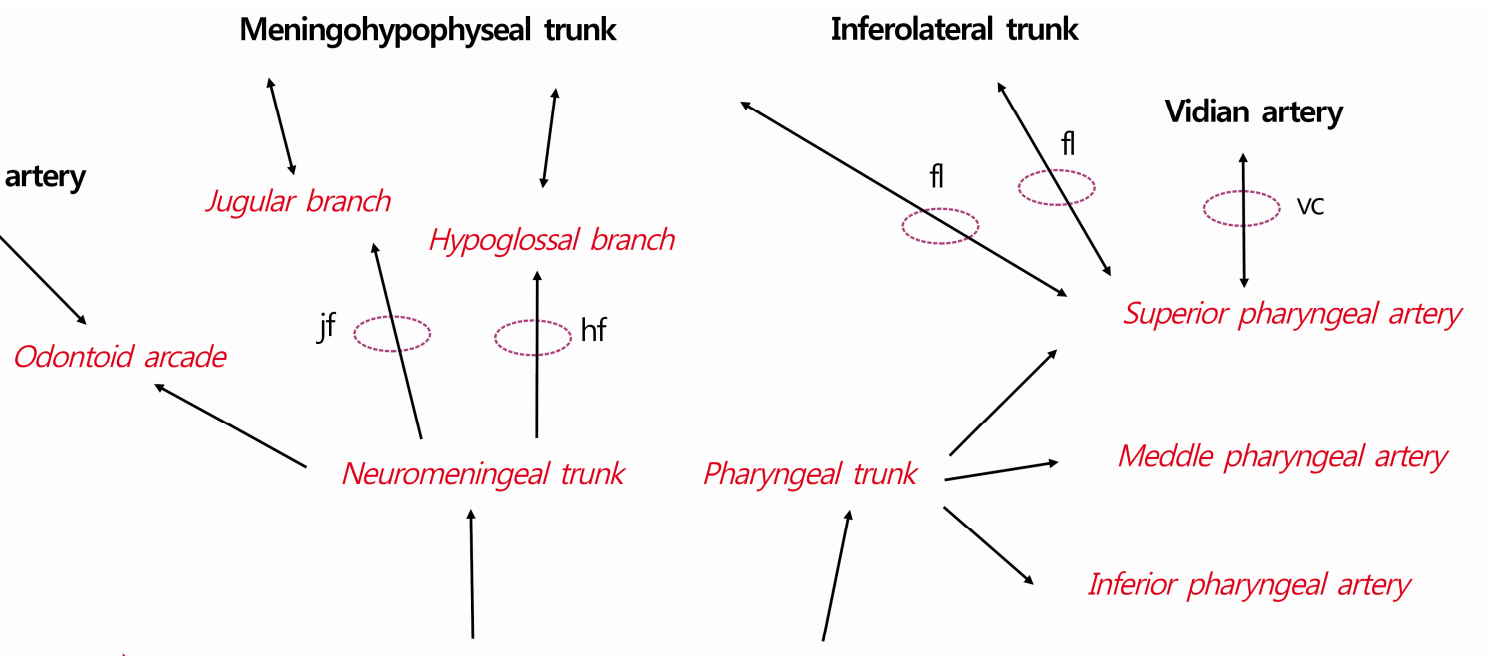

ECA
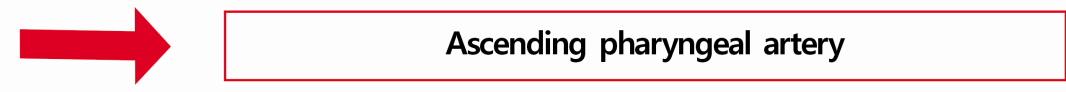

Fig. 8. Ascending pharyngeal collateral via the foramen or canal. jf, jugular foramen; hf, hypoglossal foramen; fl, foramen lacerum; vc, Vidian canal; ECA, external carotid artery.
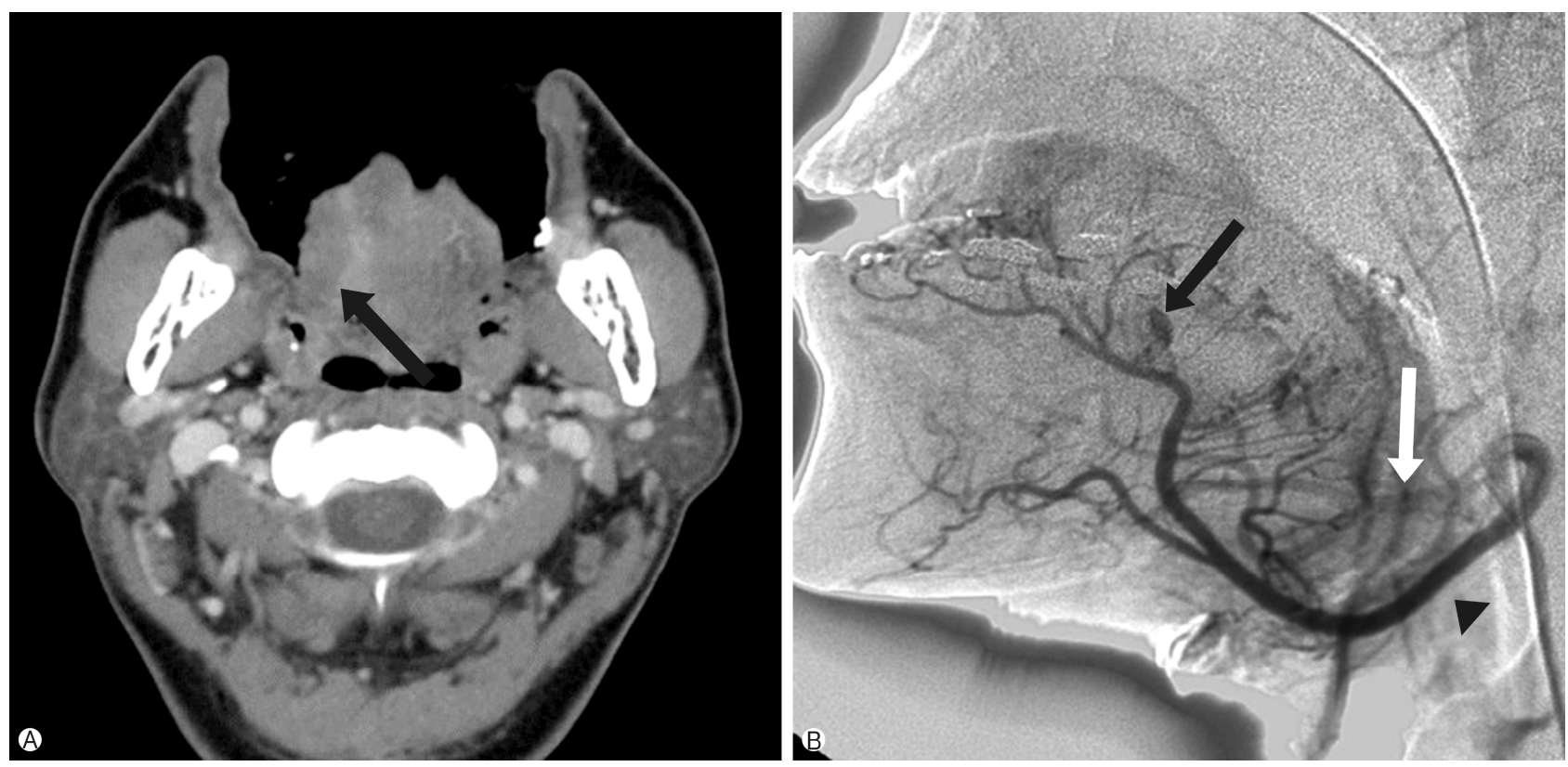

Fig. 9. A 38-year-old man with a tongue bite. (A) Computed tomography scan of the oral cavity shows the lesion of the tongue base with mixed densities (black arrow). (B) The selective angiogram (lateral view) of the right lingual artery shows a pseudoaneurysm(black arrow) from the branch of the deep lingual artery supplying the tongue. Faint facial artery (white arrow) is shown by the linguofacial collateral pathway from the lingual artery (arrow head). 
sillar branch, submental artery, and glandular branches, supplying the submandibular gland and floor of the mouth. Facial segment includes the inferior labial artery, superior labial artery, lateral nasal branch, and angular artery supplying the lips, chin, and anterior nasal cavity. According to a study, the branching patterns of the facial artery vary according to its termination. Forty-four percent has a lateral nasal artery at its termination; $36.3 \%$, angular artery; $6.6 \%$, superior labial artery; 5.5\%, inferior labial artery; and 4.4\%, forehead branch [49]. Angular artery may have anastomosis with the termination of the dorsal nasal artery of the ophthalmic artery [50,51]. Septal branch branching off superior labial artery anastomoses with the sphenopalatine and ethmoidal vessels forming the Little area that is important in the treatment of epistaxis.

Lingual artery has three branches, namely the deep lingual, dorsal lingual, and sublingual arteries supplying the anterior

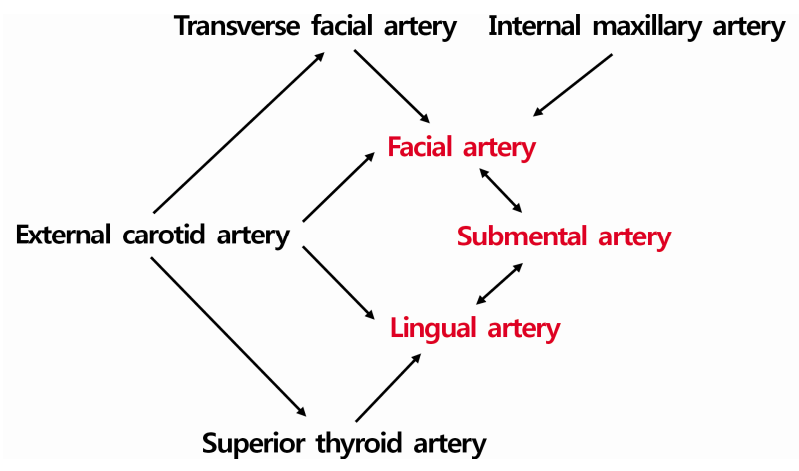

Fig. 10. Linguofacial collateral pathway. tongue, posterior tongue, and mouth floor, respectively (Fig. 9). Linguofacial collateral circle exists around the sublingual gland, anastomosing between the sublingual branch of the lingual artery and the submental branch of the facial artery (Fig. 10) [52,53]. In addition to supplying the gland, this circle gives rise to a medial mandibular branch that supplies the anterolateral surface of the body of the mandible.

Superior thyroidal artery runs anteroinferiorly and supplies the supraglottic area of the larynx branching off the infrahyoid, superior laryngeal, cricothyroid, and sternocleidomastoid arteries [54]. Intractable oronasal bleeding may occur at the damaged superior laryngeal artery (Fig. 11).

\section{CONCLUSION}

Severe craniofacial injury or tumor in the nasal or paranasal cavity may result in intractable oronasal bleeding, which is refractory to conventional treatments. Although these intractable cases subsequently can be treated with endovascular embolization of the bleeding arteries, severe complications such as visual disturbance or cerebral infarction may occur. Therefore, comprehensive understanding of the head and neck vascular anatomy is essential for more effective and safer endovascular treatment of intractable oronasal bleeding.

\section{CONFLICT OF INTEREST}

No potential conflict of interest relevant to this article was reported.
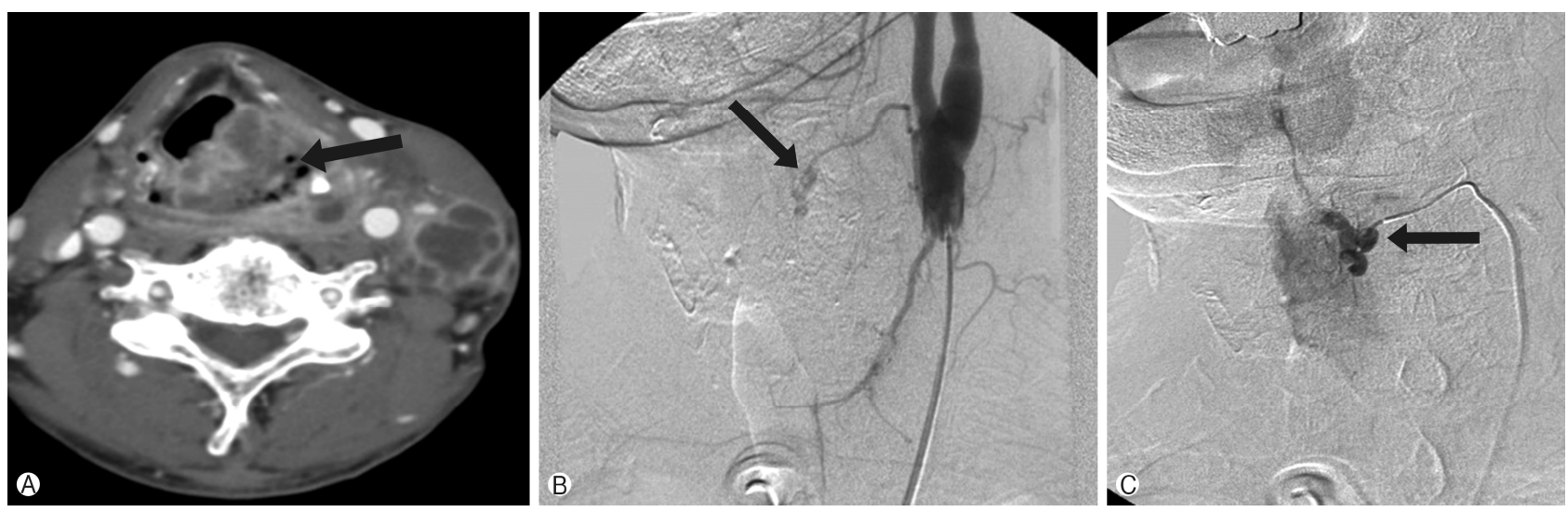

Fig. 11. A 74-year-old man with a hypopharyngeal carcinoma. (A) Contrast-enhanced neck computed tomography scan shows an enhancing mass filling the pyriform sinus (black arrow) with multiple lymph node metastases. (B, C) Right common carotid angiogram (anteroposterior view) and superselective angiogram (lateral view) of the superior laryngeal artery show a pseudoaneurysm of the superior laryngeal artery (black arrows). 


\section{ORCID}

Sungjun Moon, https://orcid.org/0000-0002-3920-7004

\section{REFERENCES}

1. Small M, Murray JA, Maran AG. A study of patients with epistaxis requiring admission to hospital. Health Bull (Edinb) 1982;40:20-9.

2. Pallin DJ, Chng YM, McKay MP, Emond JA, Pelletier AJ, Camargo CA Jr. Epidemiology of epistaxis in US emergency departments, 1992 to 2001. Ann Emerg Med 2005;46:77-81.

3. Walker TW, Macfarlane TV, McGarry GW. The epidemiology and chronobiology of epistaxis: an investigation of Scottish hospital admissions 1995-2004. Clin Otolaryngol 2007;32: 361-5.

4. Tan LK, Calhoun KH. Epistaxis. Med Clin North Am 1999; 83:43-56.

5. Viducich RA, Blanda MP, Gerson LW. Posterior epistaxis: clinical features and acute complications. Ann Emerg Med 1995;25:592-6.

6. Pollice PA, Yoder MG. Epistaxis: a retrospective review of hospitalized patients. Otolaryngol Head Neck Surg 1997;117: 49-53.

7. Klotz DA, Winkle MR, Richmon J, Hengerer AS. Surgical management of posterior epistaxis: a changing paradigm. Laryngoscope 2002;112:1577-82.

8. Schaitkin B, Strauss M, Houck JR. Epistaxis: medical versus surgical therapy: a comparison of efficacy, complications, and economic considerations. Laryngoscope 1987;97:1392-6.

9. Wehrli M, Lieberherr U, Valavanis A. Superselective embolization for intractable epistaxis: experiences with 19 patients. Clin Otolaryngol Allied Sci 1988;13:415-20.

10. Buchanan RT, Holtmann B. Severe epistaxis in facial fractures. Plast Reconstr Surg 1983;71:768-71.

11. Merland JJ, Melki JP, Chiras J, Riche MC, Hadjean E. Place of embolization in the treatment of severe epistaxis. Laryngoscope 1980;90:1694-704.

12. Cooke ET. An evaluation and clinical study of severe epistaxis treated by arterial ligation. J Laryngol Otol 1985;99:745-9.

13. Strother CM, Newton TH. Percutaneous embolization to control epistaxis in Rendu-Osler-Weber disease. Arch Otolaryngol 1976;102:58-60.

14. Hicks JN, Vitek G. Transarterial embolization to control posterior epistaxis. Laryngoscope 1989;99:1027-9.

15. Nishijima Y, Kishi H, Kurose K, Yamanaka K, Muraji T, Kin $\mathrm{K}$, et al. Hemorrhagic vascular lesions in facial injuries treated by intravascular embolization: report of two cases. No Shinkei Geka 1993;21:809-13.

16. Moser FG, Rosenblatt M, De La Cruz F, Silver C, Burde RM. Embolization of the ophthalmic artery for control of epistaxis: report of two cases. Head Neck 1992;14:308-11.

17. Willems PW, Farb RI, Agid R. Endovascular treatment of epistaxis. AJNR Am J Neuroradiol 2009;30:1637-45.
18. Osborn AG. The nasal arteries. AJR Am J Roentgenol 1978; 130:89-97.

19. Tanoue S, Kiyosue H, Mori H, Hori Y, Okahara M, Sagara Y. Maxillary artery: functional and imaging anatomy for safe and effective transcatheter treatment. Radiographics 2013;33: e209-24.

20. Krajina A, Chrobok V. Radiological diagnosis and management of epistaxis. Cardiovasc Intervent Radiol 2014;37:26-36.

21. Djindjian R, Théron J, Merland JJ. Super-selective arteriography of the external carotid artery. Berlin; New York: SpringerVerlag; 1978. p. 22-36.

22. Geibprasert S, Pongpech S, Armstrong D, Krings T. Dangerous extracranial-intracranial anastomoses and supply to the cranial nerves: vessels the neurointerventionalist needs to know. AJNR Am J Neuroradiol 2009;30:1459-68.

23. Robinson DH, Song JK, Eskridge JM. Embolization of meningohypophyseal and inferolateral branches of the cavernous internal carotid artery. AJNR Am J Neuroradiol 1999;20: 1061-7.

24. Perrini P, Cardia A, Fraser K, Lanzino G. A microsurgical study of the anatomy and course of the ophthalmic artery and its possibly dangerous anastomoses. J Neurosurg 2007;106:14250.

25. Baumel JJ, Beard DY. The accessory meningeal artery of man. J Anat 1961;95:386-402.

26. Hur MS, Kim HJ, Lee KS. Unusual course of the accessory meningeal artery. Korean J Phys Anthropol 2012;25:193-6.

27. Kasper GC, Welling RE, Wladis AR, CaJacob DE, Grisham $\mathrm{AD}$, Tomsick TA, et al. A multidisciplinary approach to carotid paragangliomas. Vasc Endovascular Surg 2006-2007;40: 467-74.

28. Hayreh SS. The ophthalmic artery: iii. branches. Br J Ophthalmol 1962;46:212-47.

29. Lurje A. On the topographical anatomy of the internal maxillary artery. Acta Anat (Basel) 1946-1947;2:219-31.

30. Quisling RG, Seeger JF. Orbital anastomoses of the anterior deep temporal artery. Neuroradiology 1975;8:259-62.

31. Chiu T. A study of the maxillary and sphenopalatine arteries in the pterygopalatine fossa and at the sphenopalatine foramen. Rhinology 2009;47:264-70.

32. Lee HY, Kim HU, Kim SS, Son EJ, Kim JW, Cho NH, et al. Surgical anatomy of the sphenopalatine artery in lateral nasal wall. Laryngoscope 2002;112:1813-8.

33. Casasco A, Houdart E, Biondi A, Jhaveri HS, Herbreteau D, Aymard A, et al. Major complications of percutaneous embolization of skull-base tumors. AJNR Am J Neuroradiol 1999; 20:179-81.

34. Lasjaunias P, Vignaud J, Hasso AN. Maxillary artery blood supply to the orbit: Normal and pathological aspects. Neuroradiology 1975;9:87-97.

35. Rysz M, Koleśnik A, Lewińska B, Ciszek B. The study of arterial anastomoses in the region of the alveolar process and the anterior maxilla wall in foetuses. Folia Morphol (Warsz) 2009;68:65-9.

36. Berenstein A, Lasjaunias P, Kricheff II. Functional anatomy of the facial vasculature in pathologic conditions and its therapeutic application. AJNR Am J Neuroradiol 1983;4:149-53. 
37. Osborn AG. The vidian artery: normal and pathologic anatomy. Radiology 1980;136:373-8.

38. Quisling RG. Intrapetrous carotid artery branches: pathological application. Radiology 1980;134:109-13.

39. Takeuchi M, Kuwayama N, Kubo M, Umemura K, Hirashima Y, Endo S. Vidian artery as a collateral channel between the external and occluded internal carotid arteries--case report. Neurol Med Chir (Tokyo) 2005;45:470-1.

40. Padget DH. The development of the cranial arteries in the human embryo. Contrib Embryol 1948;32:205-61.

41. Lasjaunias P, Moret J, Mink J. The anatomy of the inferolateral trunk (ILT) of the internal carotid artery. Neuroradiology 1977; 13:215-20.

42. Tubbs RS, Hansasuta A, Loukas M, Louis RG Jr, Shoja MM, Salter EG, et al. Branches of the petrous and cavernous segments of the internal carotid artery. Clin Anat 2007;20:596601.

43. Lasjaunias P, Moret J. The ascending pharyngeal artery: normal and pathological radioanatomy. Neuroradiology 1976; 11:77-82.

44. Hacein-Bey L, Daniels DL, Ulmer JL, Mark LP, Smith MM, Strottmann JM, et al. The ascending pharyngeal artery: branches, anastomoses, and clinical significance. AJNR Am J Neuroradiol 2002;23:1246-56.

45. Lapresle J, Lasjaunias P. Cranial nerve ischaemic arterial syndromes. A review. Brain 1986;109:207-16.
46. Lasjaunias P, Doyon D. The ascending pharyngeal artery and the blood supply of the lower cranial nerves. J Neuroradiol 1978;5:287-301.

47. Haffajee MR. A contribution by the ascending pharyngeal artery to the arterial supply of the odontoid process of the axis vertebra. Clin Anat 1997;10:14-8.

48. Lasjaunias P, Moret J, Théron J. The so-called anterior meningeal artery of the cervical vertebral artery. Normal radioanatomy and anastomoses. Neuroradiology 1978;17:51-5.

49. Yang HM, Lee YI, Lee JG, Choi YJ, Lee HJ, Lee SH, et al. Topography of superficial arteries on the face. Korean J Phys Anthropol 2013;26:131-40. Korean.

50. Lopez R, Lauwers F, Paoli JR, Boutault F, Guitard J. The vascular system of the upper eyelid. Anatomical study and clinical interest. Surg Radiol Anat 2008;30:265-9.

51. Lasjaunias PL, Berenstein A, ter Brugge KG. Surgical neuroangiography. 2nd ed. Berlin; New York: Springer; 2001.

52. Mahendrakar MA. Variation in the branching pattern of external carotid artery: a case report. J Anat Soc India 2007;56: 47-51.

53. Kalpidis CD, Setayesh RM. Hemorrhaging associated with endosseous implant placement in the anterior mandible: a review of the literature. J Periodontol 2004;75:631-45.

54. Smith TP. Embolization in the external carotid artery. J Vasc Interv Radiol 2006;17:1897-912. 